\title{
Atrioventricular dissociation with prolonged QT interval and syncopal attacks in a IO-year-old boy
}

\author{
R. J. Kernohan and P. Froggatt \\ From the Waveney Hospital, Ballymena, and The Department of Social and Preventive Medicine, The Queen's \\ University, Belfast
}

\begin{abstract}
$A$ case is reported of a Io-year-old boy with prolonged $Q T$ interval, syncopal attacks, and AV dissociation: a combination not previously described. Diagnosis and therapy are discussed.
\end{abstract}

Two heritable syndromes possibly genotypically related and manifesting prolonged QT (or QU) interval and TU wave changes, sinus bradycardia, syncopal attacks, ventricular arrhythmias, and frequently sudden death, are recognized respectively with (Jervell and Lange-Nielsen, 1957) and without (Romano, Gemme, and Pongiglione, I963; Ward, 1964) profound childhood perceptive deafness. We report here a case seemingly of the latter syndrome but with atrioventricular dissociation as the dominant rhythm. Persistent supraventricular arrhythmias are only rarely documented in these syndromes (James, 1967), and moreover the present case has other features that further warrant its report.

\section{Case report}

A 9-year-old boy was admitted to the Waveney Hospital, Ballymena, on 26 October 1971, after a spell of unconsciousness while playing in his garden the previous afternoon. His mother (a nurse) found him pale, perspiring, and unconscious but with neither convulsive movements nor incontinence. His pulse was not palpated. Recovery within 5 minutes was accompanied by facial flushing but without pronounced residual symptoms. There had been brief premonitory dizziness but neither pain nor palpitations. Three months previously while bathing in an unheated swimming pool he had his first known episode of unconsciousness and was rescued by a life-guard. He was unconscious for about $5 \mathrm{~min}-$ utes and subsequently disorientated for an equal period. He also had, since December 1970, minor episodes with pallor, epigastric discomfort, nausea, headache but no loss of consciousness, pronounced face flushing during recovery, and residual listlessness. The aetiology was unclear, but these episodes resembled in some ways the 'minor' attacks previously described in these syndromes (e.g. Fraser, Froggatt, and James, 1964a; Jervell, 1971).
On admission the patient appeared healthy, intelligent, and of normal physique. Birthweight was $2.8 \mathrm{~kg}$ after an uneventful pregnancy and confinement. Previous history and findings on systemic examination were unremarkable. Pulse rate was 55 a minute; blood pressure $90 / 60 \mathrm{mmHg}$; and there was a minimal early apical systolic murmur. On $x$-ray the cardiac silhouette was normal and cardiothoracic index 0.45 . Laboratory investigations including full blood examinations, ESR, serum electrolytes, serum magnesium, calcium and phosphorus, and blood glucose, were all normal as was an electroencephalogram and audiogram.

The electrocardiogram was abnormal showing atrioventricular dissociation with intermittent ventricular capture and a characteristically variable prolongation of the QT interval (Fig. IA and B). Long runs showed ventricular and atrial rates as, respectively, 52 and 51 a minute. $\mathbf{P}$ waves were generally upright in all limb leads but were occasionally inverted in lead III following a QRS complex, possibly indicating intermittent AV nodal dominance with retrograde atrial activation. The QT interval $\left(\mathrm{QT}_{0}\right)$ was in the range 0.48 to $0.54 \mathrm{sec}(\mathrm{RR}$ interval = $I \cdot 15 \mathrm{sec}$ ); the 'normal' $\mathrm{QT}$ interval $\left(\mathrm{QT}_{\mathrm{c}}\right)$ for this ventricular rate is $0.38 \mathrm{sec}$, as calculated from regression equation based on data from a random sample of hearing schoolboys in Belfast (Fraser, Froggatt, and Murphy, 1964b). ${ }^{1}$ Subtraction gives $\left(\mathrm{QT}_{\mathrm{o}}-\mathrm{QT} \mathrm{T}_{\mathrm{c}}\right)=0 \cdot 10$ to $0.16 \mathrm{sec}$, which is 5 to 8 times the standard error of $\mathrm{QT}_{\mathrm{c}}(=0.02 \mathrm{sec})$, a highly significant $\mathrm{QT}$ prolongation $(\mathrm{P}<0 \cdot 00 \mathrm{I})$.

On the basis of the electrocardiographic findings the spells of unconsciousness were diagnosed as syncope due to ventricular tachyarrhythmia or asystole which have been increasingly documented in these syndromes (Jervell, 1971) even when the rate-related QT prolongation is less pronounced than here (Froggatt and James, 1973).

${ }^{1} \mathrm{QT}_{\mathrm{c}}=0.099+0.486(\mathrm{RR})-0.23 \mathrm{I}(\mathrm{RR})^{2}+0.0023$ (age in years). When $R R>1.0 \mathrm{sec}, \mathrm{QT}_{\mathrm{c}}$ may be underestimated but to an unimportant extent. 


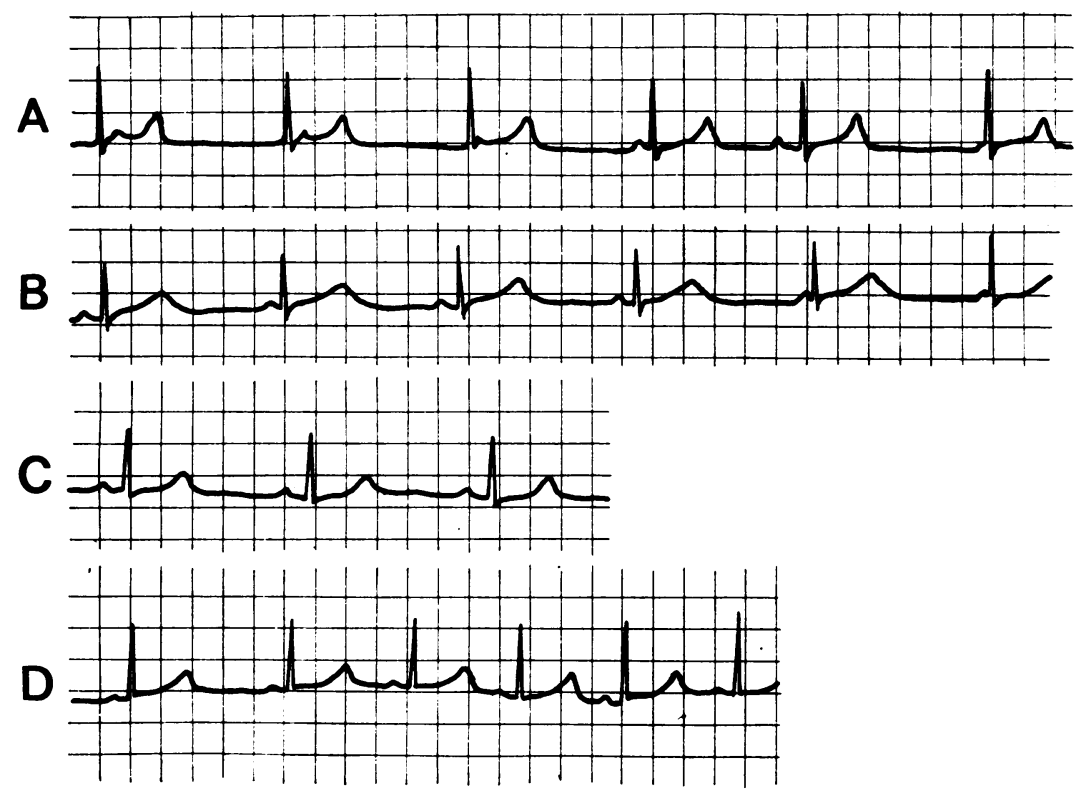

FIG. I (Paper speed is I sec $=25 \mathrm{~mm}$ ). A) Patient. Characteristic tracing (lead III) shows dominant $A V$ dissociation. Long strip averaging gives: ventricular rate 52 a minute, atrial rate $5 I$ a minute, $Q T_{\mathrm{o}}=0.48 \mathrm{sec}, Q T_{\mathrm{c}}=0.38 \mathrm{sec}, Q T_{\mathrm{o}}-Q T_{\mathrm{c}}=0.10 \mathrm{sec}(P<0.00 \mathrm{I}-\mathrm{see}$ text $)$. $P$ waves are upright in all limb leads (except aVR). B) Patient. Further strip (lead II) shows: $Q T_{\mathrm{o}}=0.54 \mathrm{sec} ; Q T_{\mathrm{c}}=0.38 \mathrm{sec} ; Q T_{\mathrm{O}}-Q T_{\mathrm{c}}=0.16 \mathrm{sec}(P<0.00 \mathrm{I})$. C) Mother (aged 34). Sinus rhythm at $5 I$ beats a minute (lead II). $Q T_{\mathrm{O}}=0.47 \mathrm{sec} ; Q T_{\mathrm{c}}$ (Ljung's (1949) formula) $=$ $0.4 \mathrm{I} \mathrm{sec} ; Q T_{\mathrm{O}}-Q T_{\mathrm{c}}=0.06 \mathrm{sec}(P<0.01)$. D) Sister (aged 13). Sinus rhythm at 74 beats a minute and pronounced sinus arrhythmia (lead $V 5) . Q T_{0}=0.45 \mathrm{sec} ; Q T_{\mathrm{c}}=0.36 \mathrm{sec} ; Q T_{\mathrm{o}}-Q T_{\mathrm{c}}$ $=0.09 \sec (P<0.001)$.

\section{Family history}

The patient is the third of 4 children ( $3 F$; IM) born to healthy unrelated parents. Information covering kinships up to the third degree gave no history of syncope, fits, unexplained or untimely sudden death, or deafness. Electrocardiograms of the first-degree relatives were normal for the father and one sister, but QT prolongation was pronounced in the mother (Fig. IC) and the eldest sister (Fig. ID) and moderate in the youngest sister $\left(\mathrm{QT}_{\mathrm{o}}-\mathrm{QT}_{\mathrm{c}}=0.05 \mathrm{sec}: \mathrm{P}=0.0 \mathrm{I}\right)$, the mother also having sinus bradycardia.

\section{Therapy}

Long-acting oral isoprenaline hydrochloride (Saventrine) was started the day after admission since it increases automaticity of the sinoatrial node, can raise the ventricular fibrillation threshold in complete AV block (Linenthal and Zoll, 1963), and can shorten the raterelated QT interval in the QT prolongation syndromes (e.g. Garza et al., 1970) and in the experimental situation. Electrocardiograms before and after discharge on $45 \mathrm{mg}$ 'saventrine' 6-hourly, showed persistence of dominant $\mathrm{AV}$ dissociation at sinus rates up to about 70 a minute, with permanent capture of sinus rhythm on one record at a rate of 120 beats a minute (Fig. $2 \mathrm{~A}$ ). The QT prolongation, however, increased (Fig. 2B), replicating the (atypical) experience of, for example, Jervell and Lange-Nielsen (1957) with adrenaline.

No further syncopal attacks occurred and the patient was readmitted on 5 February 1973 for reassessment. Saventrine was discontinued. After 5 days' monitoring to establish basic patterns and exclude significant arrhythmias, a single bolus of $0.6 \mathrm{mg}$ atropine was given intravenously. After 7 minutes, sinus rhythm was recaptured at 80 to 90 beats a minute and retained for 90 minutes before runs of AV dissociation recurred as the sinus rate slowed. QT prolongation also seemingly decreased: pre-atropine control tracing gave $Q T_{o}-Q_{c}=$ $0.12 \sec (P<0.001)$ while the average for 7 to 30 minutes post-atropine tracings was $0.06 \mathrm{sec}(P<0.01)$. After further drug-free monitoring $100 \mathrm{mg}(3 \mathrm{mg} / \mathrm{kg})$ of diphenylhydantoin was given intravenously over 5 minutes and its effect observed for 3 hours. At 20 minutes, when drug effect should be maximal (Ratshin et al., I97I), sinus rate ( 52 per minute) and sinus arrhythmia were unaffected, sinus rhythm was only intermittently recaptured, and QT prolongation was only equivocally 
A

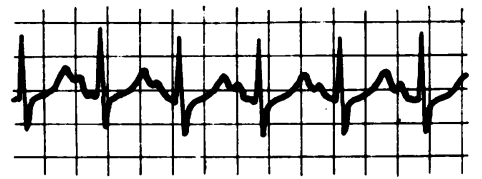

B
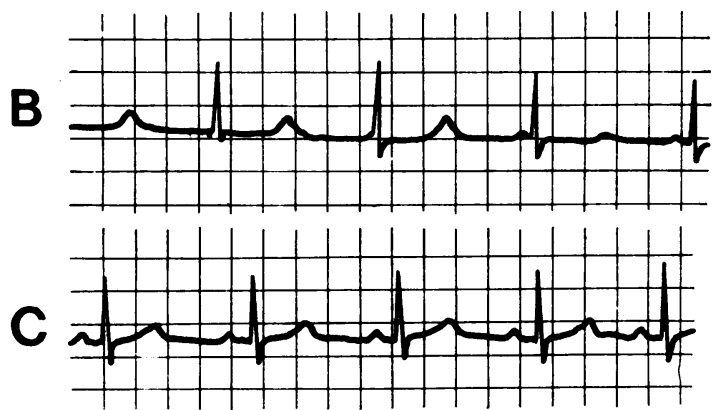

FIG. 2 (Paper speed is I sec $=25 \mathrm{~mm}$ ). A) Patient. Sinus rhythm at 120 beats a minute 4 weeks after start of 'saventrine' (lead II). $Q T_{\mathrm{o}}=0.38 \mathrm{sec} ; Q T_{\mathrm{c}}=$ $0.30 \mathrm{sec}, Q T_{\mathrm{O}}-Q T_{\mathrm{c}}=0.08 \mathrm{sec}(P<0.00 \mathrm{I})$. B $)$ Patient. $A V$ dissociation 4 days after start of 'saventrine' (lead II). Ventricular rate 60 beats a minute; $Q T_{\mathrm{o}}=0.57 \mathrm{sec} ; Q T_{\mathrm{c}}=0.37 \mathrm{sec} ; Q T_{\mathrm{o}}-Q T_{\mathrm{c}}=0.20$ $\sec (P<0.001)$. This was the longest $Q T$ interval recorded but on 'saventrine' all tracings showed $Q T_{\mathrm{O}}-Q T_{\mathrm{c}}$ in excess of Fig. IA. C) Patient. Atropine maintenance tracing (lead II). Minimal sinus arrhythmia and sinus rate of 75 beats per min. $Q T_{0}=$ $0.43 \mathrm{sec} ; Q T_{\mathrm{c}}=0.36 \mathrm{sec} ; Q T_{\mathrm{o}}-Q T_{\mathrm{c}}=0.07 \mathrm{sec}$.

reduced $\left(\mathrm{QT}_{\mathrm{o}}-\mathrm{QT}_{\mathrm{c}}=0.09 \mathrm{sec}\right.$ for pre-drug control and $=0.08 \mathrm{sec}$ for post-drug tracing at 20 minutes).

The patient was discharged on oral atropine $1.2 \mathrm{mg}$ 6-hourly after further monitoring confirmed its effect. The electrocardiogram pattern persists (Fig. $2 \mathrm{C}$ ) and the patient remains well, follows full school regimen without organized games, and has had no further attacks of unconsciousness though the 'minor' unexplained episodes continue.

\section{Discussion}

The patient seemingly manifests the heritable syndrome of QT prolongation without deafness (the Romano-Ward variant) with coexisting AV dissociation as the dominant rhythm, a combination not previously described. The classical stigmata of the syndrome are present: other known causes of QT prolongation are not (James, 1969). The QT interval though not grossly prolonged is nevertheless significantly longer than in (a) 'normal' subjects and (b) many unequivocal cases of both of the QT prolongation syndromes including some subjects with ventricular arrhythmias and/or sudden death (re- viewed in Froggatt and James, 1973). Moreover, one parent and two (of three) sibs show QT lengthening (though without syncope) consistent with Mendelian 'dominant' inheritance as now clearly demonstrated for the Romano-Ward variant (Gale et al., 1970; van der Straaten and Bruins, 1973).

The AV dissociation is unlikely to be a chance concomitant. Sinus bradycardia (and sinus arrhythmia) are common findings in the QT prolongation syndromes and the results here indicate that the AV dissociation, of the 'interference' or 'refractory' type, is their electrophysiological sequel. On this hypothesis occasional supraventricular ectopic pacemaking would occur in these syndromes and this has been documented as transient (James, 1967; Froggatt and Adgey, 1974) or, rarely, dominant patterns (James, 1967) but with persistent retrograde atrial activation, as in the 'diving reflex' in normal subjects (Whayne and Killip, 1967). The rhythm here described may simply be a rarer variant response determined by a critical relation between the absolute and relative rates in the two automatic centres.

The aim of therapy was to prevent further syncope by increasing and stabilizing sinus node automaticity and/or reducing the QT prolongation, the AV dissociation being considered innocuous per se. Most cardioactive drugs were contraindicated: digitalis can shorten the QT interval but enhances ventricular excitability; quinidine prolongs the QT interval; and practolol may block beneficial as well as unwanted adrenergic responses and intensify the bradycardia, thus predisposing to ventricular dysrhythmias (Han et al., I966a, b; Webb, Adgey, and Pantridge, 1972). Furthermore, the response to these drugs and to stellate ganglion block in QT prolongation syndromes has been inconsistent (Jervell, 1971). Atropine fulfilled the therapeutic aims more completely than did diphenylhydantoin and 'saventrine', has had no inconvenient side effects, and in this patient seems the drug of choice.

The mechanism of the QT prolongation is unknown: imbalance of adrenergic influences on the myocardium is the current favoured theory (James, 1969). The frequent coexistent sinus bradycardia may indicate a common neurogenic aetiology, especially if atropine has the rate-related QT interval shortening effect as the data here suggest. James (1967) has theorized, on the basis of histopathological findings in the sinus node and artery, a disturbance in sinus pacemaking with regular or irregular escape mechanism and atrial premature beats or arrhythmias which may trigger ventricular arrhythmias. The sinus node in this case is fully functioning and responsive which may explain the paucity of major syncopal episodes. 
Advice from Dr. Thomas N. James (University of Alabama) is gratefully acknowledged.

\section{References}

Fraser, G. R., Froggatt, P., and James, T. N. (1964a). Congenital deafness associated with electrocardiographic abnormalities, fainting attacks and sudden death. A recessive syndrome. Quarterly fournal of Medicine, 33, 361.

Fraser, G. R., Froggatt, P., and Murphy, T. (I964b). Genetical aspects of the cardio-auditory syndrome of Jervell and Lange-Nielsen (congenital deafness and electrocardiographic abnormalities). Annals of Human Genetics, 28, 133.

Froggatt, P., and Adgey, A. A. J. (1974). Clinical and therapeutic observations on a two-year-old child with the cardio-auditory syndrome (QT interval prolongation and congenital deafness) ascertained at birth. In preparation.

Froggatt, P., and James, T. N. (1973). Sudden unexpected death in infants: evidence on a lethal cardiac arrhythmia. Ulster Medical fournal, 42, 136.

Gale, G. E., Bosman, C. K., Tucker, R. B. K., and Barlow, J. B. (1970). Hereditary prolongation of QT interval: study of two families. British Heart fournal, 32, 505.

Garza, L. A., Vick, R. L., Nora, J. J., and McNamara, D. G. (I970). Heritable Q-T prolongation without deafness. Circulation, 4I, 39.

Han, J., DeTraglia, J., Millet, D., and Moe, G. K. (1966a). Incidence of ectopic beats as a function of basic rate in the ventricle. American Heart fournal, 72, 632.

Han, J., Millet, D., Chizzonitti, B., and Moe, G. K. (1966b). Temporal dispersion of recovery of excitability in atrium and ventricle as a function of heart rate. American Heart fournal, 71, $48 \mathrm{I}$.

James, T. N. (1967). Congenital deafness and cardiac arrhythmias. American fournal of Cardiology, 19, 627.

James, T. N. (1969). QT prolongation and sudden death. Modern Concepts of Cardiovascular Disease, 38, 35.

Jervell, A. (1971). Surdocardiac and related syndromes in children. Advances in Internal Medicine, 17, 425.
Jervell, A., and Lange-Nielsen, F. (1957). Congenital deafmutism, functional heart disease with prolongation of the QT interval, and sudden death. American Heart fournal, 54, 59.

Linenthal, A. J., and Zoll, P. M. (1963). Prevention of ventricular tachycardia and fibrillation by intravenous isoproterenol and epinephrine. Circulation, 27, 5.

Ljung, O. (1949). A simple formula for clinical interpretation of the QT interval. Acta Medica Scandinavica, 134, 79.

Ratshin, R. A., Hunt, D., Russell, R. O., and Rackley, C. E. (1971). QT-interval prolongation, paroxysmal ventricular arrhythmias, and convulsive syncope. Annals of Internal Medicine, 75, 919.

Romano, C., Gemme, G., and Pongiglione, R. (1963). Aritmie cardiache rare dell' eta pediatrica. II : Accessi sincopali per fibrillazione ventricolare parosisstica. (Presentazione del primo casa della letteratura pediatrica italiana.) Clinica Pediatrica (Bologna), 45, 656.

van der Straaten, P. J. C., and Bruins, C. L. D. (1973). A family with heritable electrocardiographic QT-prolongation. Fournal of Medical Genetics, 10, 158.

Ward, O. C. (1964). A new familial cardiac syndrome in children. Fournal of the Irish Medical Association, 54, 103.

Webb, S. W., Adgey, A. A. J., and Pantridge, J. F. (1972). Autonomic disturbance at onset of acute myocardial infarction. British Medical fournal, 3, 89.

Whayne, T. F., and Killip, T. (1967). Simulated diving in man: comparison of facial stimuli and response in arrhythmia. Fournal of Applied Physiology, 22, 800.

\section{Addendum}

Since preparation of this report, the patient (now on oral atropine) has had a third severe syncope, being discovered unconscious, pale, and pulseless by his mother (a nurse). Recovery followed the typical course.

Requests for reprints to Professor Peter Froggatt, Social and Preventive Medicine Department, Institute of Clinical Science, The Queen's University of Belfast, Grosvenor Road, Belfast BTI2 6BJ, Northern Ireland. 